18-20 December, 2020

Oxford, United Kingdom $11^{\text {th }}$ International Conference on

Humanities, Psychology \& Social Sciences

\title{
Does the belief in paranormal makes people less satisfied with their lives?
}

\author{
Nepryakhin N. N., Vasilyeva E. D., Avetisyan A. S. \\ Business Speech Science Research
}

\begin{abstract}
Critical thinking is often referred to as one of the most important and relevant skills of the $21 \mathrm{st}$ century. This study is aimed at identifying how this type of thinking can influence various aspects of human life. Critical thinking itself is often viewed as a combination of individual skills and attitudes. In the study, critical thinking is assessed by a short test, which requires logical thinking, but does not require academic knowledge in the field of formal logic. Also, we used a Revised Paranormal Belief Scale to assess belief in unnatural events and phenomena. These parameters were correlated with socio-demographic data, status, income level, life satisfaction and marital status. The analysis of individual subgroups revealed quite stable relationships $(\mathrm{N}=365)$. Thus, higher level of paranormal beliefs negatively affects the satisfaction of the life of top managers. Women with higher scores on the logic test correlates with a higher salary. In general, entrepreneurs and top managers were more likely to believe in the paranormal than managers and specialists. Of particular interest are the results according to which people who were divorced were more prone to paranormal thinking than people who were married and had never been married before. Most of the attention is paid to the discussion of the results obtained, their conceptual understanding, the specifics of the sample and the research procedure.
\end{abstract}

Keywords: critical thinking, paranormal thinking, superstition, life satisfaction, income, divorce, entrepreneurs, managers 